\title{
Audit in practice
}

\section{The psychiatric probation clinic}

\author{
Paul Collins, Consultant Forensic Psychiatrist, Yorkshire Regional Forensic \\ Psychiatry Service, Newton Lodge, Ouchthorpe Lane, Wakefield WF1 3SP; \\ HAdRian BALl, Consultant Forensic Psychiatrist, East Anglian Regional Forensic \\ Psychiatry Service, Norvic Clinic, St Andrews Hospital, Thorpe, Norwich NR7 0SS; \\ and ANN Costello, Probation Officer, Greater Manchester Probation Service, \\ Units 6/7 Ascroft Court, Ascroft Street, Oldham
}

Liaison with the various agencies which deal with mentally abnormal offenders is one of the prime roles of the forensic psychiatrist (Royal College of Psychiatrists, 1988). The probation service is a key agency in this regard. The importance of such collaboration has once again been highlighted with the clear message that the care of the mentally abnormal offender is improved as a result (DOH/Home Office, 1991). However, the provision of a satisfactory psychiatric consultation service to probation clients who have been remanded on bail can be problematic. Much of the work of forensic psychiatrists is institutionally based. Non-attendance rates at hospital based out-patient clinics are high (Bowden, 1978). However, general psychiatrists have found that psychiatric clinics based in general practitioners' surgeries are more acceptable to patients than hospital clinics (Tyrer, 1984). The probation office as a community base for forensic psychiatrists is a valid equivalent.

This paper describes the referrals to a weekly psychiatric probation clinic held in a probation office in Oldham Metropolitan District over two years.

\section{The clinic}

The probation service in Oldham is part of the Greater Manchester Probation Service and is based in a large, three storey building on Rochdale Road approximately one mile from Oldham Town Centre. At any one time there are about 500 cases requiring the active involvement of its 13 probation officers. During the period of this study (August 1989 to July 1991) a senior registrar in forensic psychiatry from the Edenfield Regional Secure Unit in Manchester held a weekly out-patient clinic in the building. The purpose of the clinic was to provide open access to psychiatric assessment for the probation clients and advice to the probation staff. A clinical psychologist from the local mental health services held a fort- nightly clinic in the office next door to the psychiatrist. Referrals were co-ordinated by a probation officer with a particular interest in mental health matters.

\section{The probation clients}

Forty-seven probation clients were referred to one of the psychiatrists during the two years covered by the study; 45 attended for psychiatric interview. Data collected included details of age, sex, current offence, psychiatric history, current psychiatric treatment, reason for referral, psychiatric diagnosis, and outcome of the assessment. Thirty-eight men and seven women were referred during the two years of the study. The referrals came largely from the probation service (37) with a small number from other sources-self referrals (3), solicitors (2), other forensic psychiatrists (2), and social services (1).

The usual reason for referral was a request for an assessment of mental state, including dangerousness, (36). Six referrals included a request for treatment, either as a condition of a probation order or parole licence or as part of the community follow-up of recently discharged patients of the regional forensic service who lived in the Oldham district. Finally, three referrals were for medico-legal reports.

The ages of the probation clients ranged from 16 to 58 with more than $50 \%$ of referrals consisting of clients over 30 years of age. In general, the current and previous offences tended towards the lower end of the spectrum of seriousness (assault, acquisitive, motoring and public order offences), but included more serious personal violence and sex offences. Most clients were not currently receiving psychiatric treatment, although almost half had previously been psychiatric patients. Personality disorder $(38 \%)$ and alcohol or drug dependency $(20 \%)$ featured strongly as the primary diagnosis recorded by the psychiatrist at the probation clinic; $15 \%$ had a chronic psychosis. 
Only 12 of the 45 probation clients seen at the clinic were considered not to need follow-up appointments. Twenty-one were offered follow-up appointments at the probation clinic, while 12 were referred to local psychiatric services. Seven follow-up appointments at the probation clinic were not kept. Therefore, of 68 first or second appointments made at the clinic, 59 were taken up $(87 \%)$.

\section{Comment}

A certain tension had previously characterised relationships between the local psychiatric and probation services. This may have been due to the probation service lobbying for resources on behalf of an often unpopular client group. Establishing the clinic has led to a growth in mutual understanding and confidence.

Forty-five new cases seen over two years is not many, but it is similar to the referral pattern found in a psychiatric clinic in a London probation office (Bowden, 1978). However, the non-attendance rate for first appointment of only $4 \%$ and for first and subsequent appointment of $13 \%$ is excellent and compares favourably with the $17.5 \%$ found in a general psychiatric clinic (Thapar \& Ghosh, 1991) and the one third of referrals to a forensic clinic in a hospital setting (Bowden, 1978). The impression was that probation clients found the setting of the clinic acceptable to them, and that they found it easier to disclose information in a building in which they were accustomed to meeting with their probation officer. In addition, social and criminal histories were to hand, and supervising officers were available for discussion of the case with the psychiatrist.

The preponderance of males to females referred reflects the sex distribution among law breakers generally. Similarly, the lower level of seriousness of the offences would be expected among offenders who have been given probation rather than a custodial sentence.

Nearly three-quarters of the probation clients were offered further psychiatric contact, suggesting that the probation officers were sensitive to a significant need for psychiatric care among their clients. However, the clinic provided benefits not only to the consumers but also to the providers of the service. The psychiatrists gained greater insight into the workings of the probation service, particularly from the opportunity to discuss cases informally with supervising officers. In the increasing drive towards community psychiatry the clinic provided one of the few opportunities for the forensic psychiatrists to leave the institution and try to deliver mental health care in a setting where the patient was prepared to accept it.

The probation officers gained greater confidence in the management of personality disordered patients, realising that in fact they had always dealt with this group, but now had additional support from the mental health services. The probation officers came to appreciate the inappropriateness of seeking hospital admission in most cases and instead requested assessments of dangerousness and treatability through the clinic where possible. Local magistrates were made aware of the facility and often postponed the disposal of a case pending an assessment at the clinic. This was usually done without the need formally to request a medico-legal report; rather the psychiatric assessment assisted the probation officer in subsequent recommendations to the court. However, referral rates which average one new patient every two weeks make it difficult to justify a weekly clinic. Also, one of the disadvantages of being in a community clinic is the potential waste of time when people default from appointments. In hospital settings it may be easier to make more efficient use of the time.

Certain ethical issues also arise. Patients seen at the clinic were not referred by their general practitioner, who more often than not was unaware that the referral had been made. In several psychiatric specialties (including forensic psychiatry, child psychiatry and mental handicap) it is current practice for the hospital services to accept referrals directly from a variety of non-medical organisations. However, it is generally accepted and recognised by the General Medical Council that hospital specialists should assess and treat only patients who have been referred by a general practitioner.

As a corollary of the above, who will pay for such a service now that the NHS reforms are operational? Purchasing authorities might be unhappy at the probation service referring patients to a specialist service without their consent. Will this mean the disappearance of psychiatric probation clinics and a return to the high non-attendance rates of hospital clinics? Perhaps the solution would be for the Home Office to fund such clinics since the probation service falls within its administrative remit.

\section{References}

BowDEN, P. (1978) A psychiatric clinic in a probation office. British Journal of Psychiatry, 133, 448-451.

DOH AND HOME OFFICE (1991) Review of Health and Social Services for Mentally Disordered Offenders and Others Requiring Similar Services: Report of the Community Advisory Group.

RoYAl COLLEGE OF PSYCHIATRISTS(1988) The role, responsibilities and work of the consultant forensic psychiatrist: a discussion document. Bulletin of the Royal College of Psychiatrists, 12, 246-249.

ThAPAR, A.\& GHOSH, A. (1991) Non-attendance at a psychiatric clinic. Psychiatric Bulletin, 15, 205-206.

TYRER, P. (1984) Psychiatric clinics in general practice: an extension of community care. British Journal of Psychiatry, 145, 9-14. 